EREM 76/2

Journal of Environmental Research, Engineering and Management Vol. 76 / No. 2 / 2020 pp. 6-21

DOI 10.5755/j01.erem.76.2.20299
The Modified DISPRIN Model for Transforming Daily Rainfall-Runoff Data Series on a Small Watershed in Archipelagic Region

Received 2018/03

Accepted after revision 2020/06

\title{
The Modified DISPRIN Model for Transforming Daily Rainfall-Runoff Data Series on a Small Watershed in Archipelagic Region
}

\section{Sulianto*}

Department of Civil Engineering, University of Muhammadiyah Malang, East Java-Indonesia

\section{Muhammad Bisri, Lily Montarcih Limantara, Dian Sisinggih}

Department of Water Resources Engineering, University of Brawijaya Malang, East Java-Indonesia

*Corresponding author: sulianto1967@gmail.com

The existence of the translation effect component on the application of the original Dee Investigation Simulation Program for Regulating Network (DISPRIN) model would be counter-productive when applied to rainfall-runoff analysis on small watersheds that have the level of sharp fluctuations that commonly occur in tropical islands. Modifying the original DISPRIN model by ignoring the components proved to mask existing weaknesses. This article tries to compare the performance of the original DISPRIN model and the modified DISPRIN model in the case of the transformation of rainfall data series into discharge data series on a daily period. The calibration process of the parameters of both models uses the evolution differential algorithm (DE). The case study is Lesti watershed at the control point of AWLR Tawangrejeni station $\left(319.14 \mathrm{~km}^{2}\right)$ located in East Java, Indonesia. The test model uses 10-year daily data sets, from January 1, 2007, to December 31, 2016. Data series from 2007 to 2013 as a training data set used for the process of model calibration and model validation, data series from 2014 to 2016 as a test data set for model verification. The results show that the modified DISPRIN model is more effective than the original DISPRIN model in terms of accuracy and iteration time in achieving convergent conditions. The original DISPRIN model was able to respond to fluctuations in a seasonal flow, but was unable to respond to the sharp fluctuations in daily flows. The modified DISPRIN model can fix that vulnerability and can generate an NSE > 0.8 value in the validation and verification phase.

Keywords: differential evolution algorithm, modified disprin model, rainfall, runoff. 


\section{Introduction}

The fundamental weakness of the application of the lumped model in conceptual hydrological lies in the large number of parameters that must be calibrated simultaneously before the model can be applied. This makes the model ineffective in solving practical problems. Efforts to improve the performance of lumped models by combining them with concepts of metaheuristic-based optimisation have been widely proposed by world researchers. Several new models of combined lumped models and metaheuristic methods have been developed, including the differential evolution (DE) algorithm and particle swam optimisation (PSO) algorithm combined with HBV model and GRJ4 model (Piotrowski et al,. 2016), genetic algorithm (GA) with NAM model and Tank model (Ngoc et al., 2012), GA with HBV modified model (Saibert, 2000), CTSM algorithm with HBV model and NAM model (Jonsdottir et al., 2005), GA with HBV modified model (Saibert, 2000), shuffle complex evolution (SCE) algorithm with AFFDEF model (Darikandeh, 2014), dynamically dimensioned search (DDS) algorithm and SCE algorithm with SWAT 2000 model (Tolson and Shoemaker, 2007), Xin'anjiang model with SCE algorithms (Bao et al., 2008), as well as GA and GA hybrid (Wang et al., 2012). Metaheuristic methods for automatic calibration of Tank model parameters have also been proposed, including a combination Tank model with PSO algorithm (Santos et al., 2011), Marquard algorithm (Setiawan et al., 2003), and GA (Ngoc et al., 2012). The combination of Tank models with the PSO algorithm for flood discharge analysis with the hour-time period in urban areas in Taiwan can perform very well (Hsu and Yeh, 2015). A multi Tank model of 6 tank system (27 parameters) combined with the DDS algorithm can show better results than the finite element method (FEM) model (Uhlenbrook et al., 1999). The Tank model of 8 tank system (32 parameters) combined with the DDS algorithm and GA can perform well in predicting groundwater fluctuations in Yamagata, Japan. In this case, the two developed models can show nearly the same error rate, but the DDS algorithm-based optimisation method is more effective in speed of reaching convergent conditions (Huang and Xiong, 2010).
The DISPRIN or Dee Investigation Simulation Program for Regulating Network model as explained by Jamieson and Wilkinson (1972) is included in the lumped model category (Shaw, 1985). In applying the DISPRIN model, a watershed must be divided into three zones, namely up-land zone, hill-slope zone and bottom slope zone. The process of transformation rainfall into runoff data was approached by applying 8 tanks spread across the three zones in the watershed. This article is basically part of a study entitled DISPRIN model with Automatic Calibration Based on Differential Evolution Algorithm Based on Transforming Rain Data Into Runoff, that has been done by the author. Efforts to improve the performance of the DISPRIN model are done by involving the optimisation process of parameters by utilising the advantages of the DE algorithm. This research was carried out in two stages. Stage 1 is directed at efforts to improve the performance of the original DISPRIN model to transform rainfall data series into runoff data series by using a weekly period input data set. Evapotranspiration data and rainfall data are accumulated from daily data in a week ( $\mathrm{mm} /$ week). The discharge data used are the average data from recording daily discharges $\left(\mathrm{m}^{3} / \mathrm{s}\right)$ so that sharp discharge fluctuations due to short periods of hard rain do not appear. By using this data input set, the original DISPRIN model can show good performance. The discharge curve from the model output can approach the observation discharge curve, both at the validation and verification stages. The new model resulting from the merging of the original DISPRIN model equation system with the DE algorithm is called the DISPRIN25-DE model. Index 25 shows the number of parameters involved in the optimisation process. Stage 1 research results have been published in the Journal of Water and Land Development No. 37 (pp. 141-152), with the article entitled Automatic calibration and sensitivity analysis of DISPRIN model parameters: A case study on Lesti watershed in East Java, Indonesia (Sulianto et al., 2018).

This article is the result of stage 2 research directed at efforts to improve the performance of the DISPRIN model in anticipating the occurrence of sharp flow 
fluctuations in the short period that characterises hydrographs in rivers that have small watersheds in the tropics, as well as the characteristics of rivers in Indonesia. The results of the sensitivity analysis of the original DISPRIN model parameters using the Monte Carlo simulation method show that the parameters on the translation effect factor have a very high sensitivity level and are very low on other parameters. This indicates that the performance of the original DISPRIN model is strongly influenced by the accuracy in determining the values of these parameters (Sulianto et al., 2018). In large watersheds that have long river channels and wide cross sections as the Dee river character, in which the model was developed, the translation effect factor may have a positive effect on the model's performance. However, if applied to rivers in an archipelago that has a small watershed with a fast flow response, this factor can actually negatively affect the performance of the model. The success of the Tank model by Sugawara in anticipating this phenomenon by negating the translation effect factor in the analysis process may be accommodated in order

\section{Materials and methods}

\section{Hydrological model}

Schematic simulation of the original DISPRIN model and the modified DISPRIN model are shown in Figure 1. The application of the original DISPRIN model involves 8 tanks including tank $\mathrm{H}$ that presents the translation effect factor, so that the river discharge is identical to the outflow from tank $\mathrm{H}$. The modified DISPRIN model consists of 7 tanks (without involving tank $H$ ), so the river discharge is the result of the sum of horizontal outflows from tank $E$, tank F and tank $G$.

The boundaries of up-land zones, hill-slope zones and bottom-slope zones on watersheds are determined based on their position and physical characteristics that can be interpreted from topographic maps. The up-land zone is located in an upstream basin that is physically sloped with a steep surface, the hill-slope zone is located in the central basin with the medium surface, and the bottom-slope zone is located downstream of the watershed, which tends to have a flat surface slope. Each watershed zone is presented by to improve the performance of the original DISPRIN model. Therefore, a modification of the DISPRIN model by ignoring these factors to be relevant is proposed in this study. Thus, the DISPRIN model may be modified into 7 tanks with 23 parameters, or called the DISPRIN23 model. The merging of the DISPRIN23 model equation system with the DE algorithm is then called the DISPRIN23-DE model.

Model testing was carried out at the same research location as stage 1 research (Lesti watershed, 319.14 $\mathrm{km}^{2}$ ), but the data period used as a basic for analysis was different. Evapotranspiration and rainfall use daily recording data $\left(\mathrm{mm} /\right.$ day). Discharge data $\left(\mathrm{m}^{3} / \mathrm{s}\right)$ refer to the average discharge from recording the hourly period obtained from the automatic water level record (AWLR) so that the sharp flow fluctuation curve due to short periods of rainfall is clearly visible. The overall results of the study are expected to be an alternative solution to help solve the problem of limited river flow data, which often becomes an obstacle in water resource development activities in developing countries, including Indonesia.

two vertical series of tanks. In a watershed system the upper tank contributes to surface flow and intermediate flow. The bottom tank is a reservoir sub-base that contributes to the flow of the sub-base flow. The tanks in each watershed zone are interconnected with the principle of gravity flow. The horizontal outflow from the up-land zone tank group will flow in the hillslope zone tank group, and then the hill-slope zone tank group will fill the water in the bottom slope zone. In the vertical upstream, the upper tank will fill the bottom tank when sufficient water supply is available. However, if evapotranspiration is so dominant that it cannot be fulfilled by the upper tank water reserves, the water reserves in the lower tanks will be taken at the value of the deficit. This process also applies to the hill-slope zone and bottom-slope zone tank.

Based on Figure 1, the parameters of the original DISPRIN model and the modified DISPRIN model can be identified as shown in Table 1. These parameters 
Fig. 1. Simulation scheme of the DISPRIN model

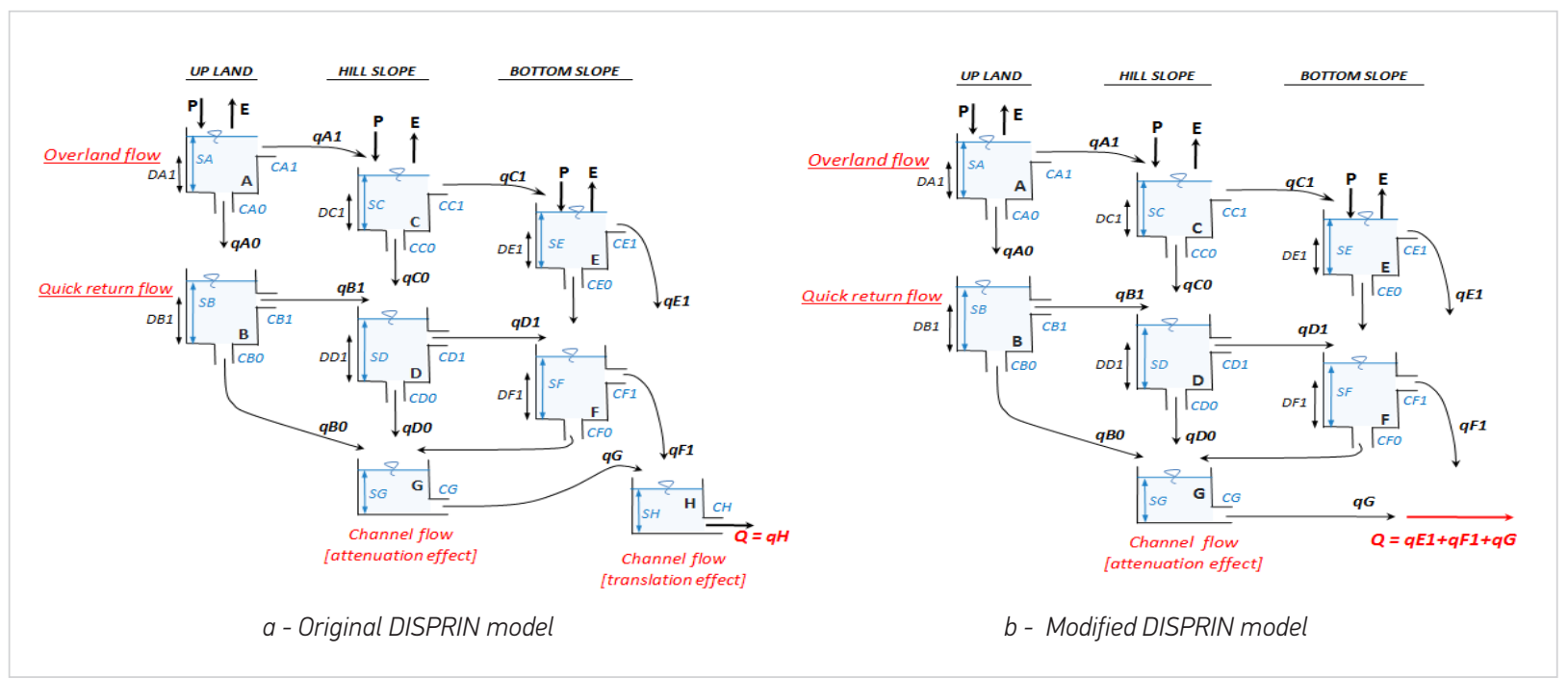

are basically the physical characteristics of each tank as an analogy of the physical characteristics of the watershed parts. In the DISPRIN model application, the physical characteristics are expressed as the discharge coefficient on the tank hole, the height of the tank hole and the initial height of the water level in the tank. The original DISPRIN model according to Figure 1a) has 25 parameters spread over 8 tanks. The upland zone, the hill-slope zone and the bottom-slope zone each have 7 parameters. The attenuation effect and the translation effect each have 2 parameters. In this model, the runoff function can be stated more simply because it is identical to the amount of horizontal flow through tank $\mathrm{H}$. The modified DISPRIN model according to Figure $1 \mathrm{~b}$ ) has a slightly different tank structure. This model does not involve the translation effect factor so that it only consists of 7 tanks and has 23 parameters. In this model, the river flow function is the sum of the horizontal flow of tank $E$, tank $F$ and tank $G$.

As shown in Figure 1, initially the water can fill the top tank or even go out of the tank corresponding to climatic conditions. When the period of rainfall is greater than evapotranspiration, the top tank in all three zones will experience the charging amount of the difference between the amount of rainfall and evapotranspiration values $[P(t)-E P(t)]$. But if it turns out that the evapotranspiration period is more dominant than rainfall, then precisely the water level in the tank will shrink as the difference between the value of evapotranspiration and rainfall that happened during that period $[E p(t)-P(t)]$.

The horizontal flow of tank $A(q A 1)$ as the surface flow will occur when the water level position in tank A exceeds the position of the horizontal outlet. The runoff value is expressed as follows:

$$
q A 1(t)=S A_{\text {maen }}(t)-D A 1
$$

Vertical flow of tank $A$ ( $q A 0$ ) presents the infiltration process and will occur if there is sufficient water in the tank.

The flow will increase the water level of tank B. The infiltration flow $q A O(t)$ can be calculated by the equation:

$$
q A O(t)=c A O * S A_{\text {mean }}(t)
$$

$$
S A_{\text {mean }}(t)=[(S A(t-1)+S A(t)] / 2
$$

Where: $c A 0$ - discharge coefficient bottom outlet tank $A$; $S A(t)$ - height of water level tank A period $t(\mathrm{~mm})$; $S A(t-1)$ - height of water level tank A period t-1 (mm). 
Table 1. Parameters of original DISPRIN model and modified DISPRIN model

\begin{tabular}{|c|c|c|c|c|c|}
\hline \multirow{2}{*}{ Zone } & \multirow{2}{*}{ Tank identity } & \multirow{2}{*}{ Description of flow } & \multicolumn{2}{|c|}{ DISPRIN model parameters } & \multirow{2}{*}{ Description of model parameters } \\
\hline & & & Original & Modified & \\
\hline \multirow{7}{*}{ Up-land } & \multirow{3}{*}{$A$} & \multirow{3}{*}{ Overland flow } & CAO & CAO & Coefficient of infiltration flow \\
\hline & & & $D A 1$ & $D A 1$ & Height of overland flow outlet \\
\hline & & & $S A$ & $S A$ & Initial of water level in tank $A$ \\
\hline & \multirow{4}{*}{$\mathrm{B}$} & \multirow{4}{*}{ Quick return flow } & CBO & CBO & Coefficient of percolation flow \\
\hline & & & $C B 1$ & CB1 & Coefficient of subsurface flow \\
\hline & & & $D B 1$ & $D B 1$ & Height of subsurface flow outlet \\
\hline & & & $S B$ & $S B$ & Initial of water level in tank $B$ \\
\hline \multirow{7}{*}{ Hill-slope } & \multirow{3}{*}{ C } & \multirow{3}{*}{ Overland flow } & $\mathrm{CCO}$ & $\mathrm{CCO}$ & Coefficient of infiltration flow \\
\hline & & & $D C 1$ & $D C 1$ & Height of overland flow outlet \\
\hline & & & SC & SC & Initial of water level in tank C \\
\hline & \multirow{4}{*}{$\mathrm{D}$} & \multirow{4}{*}{ Quick return flow } & CDO & CDO & Coefficient of percolation flow \\
\hline & & & CD1 & $C D 1$ & Coefficient of subsurface flow \\
\hline & & & $D D 1$ & $D D 1$ & Height of subsurface flow outlet \\
\hline & & & $S D$ & $S D$ & Initial of water level in tank $D$ \\
\hline \multirow{11}{*}{ Bottom-slope } & \multirow{3}{*}{$\mathrm{E}$} & \multirow{3}{*}{ Overland flow } & CEO & CEO & Coefficient of infiltration flow \\
\hline & & & $D E 1$ & $D E 1$ & Height of overland flow outlet \\
\hline & & & SE & SE & Initial of water level in tank $E$ \\
\hline & \multirow{4}{*}{$\mathrm{F}$} & \multirow{4}{*}{ Quick return flow } & CFO & CFO & Coefficient of percolation flow \\
\hline & & & CF1 & CF1 & Coefficient of subsurface flow \\
\hline & & & $D F 1$ & $D F 1$ & Height of subsurface flow outlet \\
\hline & & & SF & SF & Initial of water level in tank $F$ \\
\hline & \multirow{2}{*}{ G } & \multirow{2}{*}{ Attenuation effect } & $C G$ & $C G$ & Coefficient of runoff \\
\hline & & & SG & SG & Initial of water level in tank $G$ \\
\hline & \multirow{2}{*}{$\mathrm{H}$} & \multirow{2}{*}{ Translation effect } & $\mathrm{CH}$ & & Coefficient of runoff \\
\hline & & & SH & & Initial of water level in tank $\mathrm{H}$ \\
\hline \multicolumn{5}{|c|}{ Original DISPRIN model } & Modified DISPRIN model \\
\hline \multicolumn{3}{|c|}{ Runoff river function } & \multicolumn{2}{|c|}{$Q(t)=Q_{H}(t)$} & $Q(t)=Q_{E 1}(t)+Q_{F 1}(t)+Q_{G}(t)$ \\
\hline
\end{tabular}


In the same period, the second tank on the up-land zone (Tank B) will also experience changes in water reserves. Adding $q A O(t)$ will occur when the flow is positive, but if $q A O(t)$ is negative it means that the water reservoir in tank $A$ is not sufficient to meet the evapotranspiration process needs and the value must be taken from the water reserve in tank $B$. The height of water level tank $B$ in period $t$ can be expressed as:

if, $q A O \geq 0$, then

$$
S B(t)=S B(t-1)+q A O(t)
$$

and if, $q A O<0$, then:

$S B(t)=S B(t-1)-[E p(t)-P(t)-S A(t)]$

The horizontal flow (qB1) as the sub-base flow will occur when the water position in tank $B$ is higher than the horizontal outlet position $(S B(t)>D B 1)$. The flow that occurs is expressed as:

$S B(t)=S B(t-1)-[E p(t)-P(t)-S A(t)]$

$q B 1(t)$ will fill the tank $D$. Since the area of the up-land zone and the hill-slope zone is different, the flow into tank $\mathrm{D}$ can be proportionally computed by the equation:

$q B 1 t(t)=(A u / A h) * q B 1(t)$

Where: $q B 1 t(t)$ - inflow to tank $D(\mathrm{~mm} /$ day);

$A u$ - area of up-land zone $\left(\mathrm{km}^{2}\right)$;

$A h$ - area of the hill-slope zone $\left(\mathrm{km}^{2}\right)$.

The vertical flow of tank $B$ describes the percolation process in the soil. This flow will fill the deep ground water reserves. The vertical flow $(q B 0)$ can be calculated by the equation:

$$
q B O(t)=c B O * S B_{\text {mean }}(t)
$$

The percolation flow will further increase the deep ground water reserve (tank G). Since the area of the up-land zone and the total area of the watershed is different, the flow into tank $G$ proportionally can be calculated by the equation:

$$
q B O t(t)=(A u / A w) * q B O(t)
$$

Where: $q B 0 t(t)$ - inflow to tank $\mathrm{G}(\mathrm{mm} /$ day); $A w$ - watershed total area $\left(\mathrm{km}^{2}\right)$.
The flow calculation procedure in the hill-slope zone of the tank system and the bottom-slope zone by analogy can follow the above principles with respect to the flow configuration as described in Figure 1.

Tank $G$ accommodates the channel flow factor in a component attenuation effect. The water reservoir in this tank is not affected by the evapotranspiration process. Water filling in tank $G$ is only influenced by the percolation flow of the three watershed zones. At the beginning of the dry season, the base flow in the river is caused by the intermediate flow and subbase flow components. However, at the end of the dry season when the water reserves in the intermediate zone have been exhausted to meet evapotranspiration needs, the river flow is only supported by tank $G$. The height of the water level in tank $G$ is stated as:

$S G(t)=S G(t-1)+q B O t(t)+q D O t(t)+q F O t(t)$
$q B O t(t)=(A u / A w)^{*} q B O(t)$
$q D O t(t)=(A h / A w)^{*} q D O(t)$
$q F O t(t)=(A b / A w)^{*} q F O(t)$

Where: $S G(t)$ - height of water level tank $G$ period $t(\mathrm{~mm})$; $S G(t-1)$ - height of water level tank $G$ period $(\mathrm{t}-1)(\mathrm{mm})$; $q D O(t)$ - vertical outflow tank D period $\mathrm{t}(\mathrm{mm} /$ day); $q F O(t)$ - vertical outflow tank $F$ period $t(\mathrm{~mm} /$ day); $q B O t(t)$ - inflow from tank $B$ to tank $G$ period $t(\mathrm{~mm} /$ day); $q D O t(t)$ - inflow from tank $D$ to tank $G$ period $t(\mathrm{~mm} /$ day); $q F O t(t)$ - inflow from tank $F$ to tank $G$ period $t(\mathrm{~mm} /$ day).

The outflow of tank $G$ can be stated as:

$q G(t)=c G * S G_{\text {mean }}(t)$
$S G_{\text {mean }}(t)=[(S G(t-1)+S G(t)] / 2$

As shown in Figure 1a), the stream flow of the original DISPRIN model (DISPRIN25 model) can be expressed as:

$q(t)=q H(t)=C H^{*} S H_{\text {mean }}(t)$
$S H_{\text {mean }}(t)=[(S H(t-1)+S H(t)] / 2$
$S H(t)=q E 1 t(t)+q F 1 t(t)+q G(t)$


In the modified DISPRIN model (DISPRIN23 model), the stream flow can be expressed as:

$q(t)=q G(t)+q E 1 t(t)+q F 1 t(t)$
$q E 1 t(t)=(A b / A w)^{*} q E 1(t)$
$q F 1 t(t)=(A b / A w)^{*} q F 1(t)$

Where: $q(\mathrm{t})=\mathrm{qH}(\mathrm{t})-$ stream flow period $\mathrm{t}(\mathrm{mm} /$ day $)$; $\mathrm{CH}$ - outlet coefficient tank $\mathrm{H}$;

$S H(t)$ - height of water level tank $H$ period $t(\mathrm{~mm})$;

$S H(t-1)$ - height of water level tank H period t-1 (mm); $q G(t)$ - outflow from tank $G$ period $t(\mathrm{~mm} /$ day); $q E 1(t)$ - outflow from tank E period $\mathrm{t}(\mathrm{mm} /$ day); $q F 1(t)$ - outflow from tank $F$ period $t(\mathrm{~mm} /$ day); $q E 1 t(t)$ - inflow to tank $\mathrm{H}$ from tank $\mathrm{E}(\mathrm{mm} /$ day); $q F 1 t(t)$ - inflow to tank $\mathrm{H}$ from tank $\mathrm{F}$ ( $\mathrm{mm} /$ day). $q(t)$ is the river flow of period $t$ at the watershed control point in $\mathrm{mm} /$ day, river flow in units of $\mathrm{m}^{3} / \mathrm{sec}$ is expressed as:

$Q(t)=A W^{*} q(t) /(86.4)$

\section{Calibration model}

The parameter calibration model is an analogy of solving the optimisation problem to produce the optimal value of the DISPRIN model parameters. The objective function of the optimisation process is the minimisation of deviation between the data training debit curve and the debit curve of the model simulation result. In the metaheuristic method, the objective function is expressed as the fitness value. The definition of the fitness value in the case of hydrological model parameter optimisation has been widely proposed by previous researchers, including minimisation of the root mean square error (RMSE) (Hsu and Yeh, 2015; Zhang $X$ et al., 2012; Sulianto et al., 2018), minimisation of the sum square error (SSE) [Setiawan et al., 2003; Kim Oong $\mathrm{H}$ et al., 2005), maximisation of the Nash-Sutcliffe (NS) efficiency (Zhang et al., 2008; Bao et al., 2008; Uhlenbrook et al., 1999), the maximisation of the inverse mean square error (MSE) ( $\mathrm{Ngoc}$ et al., 2012), minimisation of the relative error (RE) (Santos, 2011; Kuok King et al., 2011). In this article, the fitness value is expressed as the RMSE minimisation calculated by the equation:

$$
F=R M S E=\sqrt{\frac{1}{N} \sum_{t=1}^{N}\left[Q_{\text {train }, t}-Q_{\text {sim }, t}\right]^{2}}
$$

Where: $F$ - fitness function, RMSE - root mean square error $\left(\mathrm{m}^{3} / \mathrm{s}\right)$;

$Q_{\text {sim,t }}-$ discharge from simulated in period $t\left(\mathrm{~m}^{3} / \mathrm{s}\right)$;

$Q_{\text {train,t }}$ - discharge from data training in period $\mathrm{t}\left(\mathrm{m}^{3} / \mathrm{s}\right)$; $N$ - number of data points.

In this article, the problem solving optimisation is done by using the DE algorithm. The DE algorithm is a combination between stochastic and population based search methods. DE has similarities with other evolutionary algorithms (EA), but differs in terms of distance and direction information from the current population used to guide the process of finding a better solution (Storn and Price, 1997). The DE algorithm contains 4 components, namely 1) initialization, 2) mutation, 3) recombination or crossover and 4) selection.

The relationship between the DE algorithm component and the DISPRIN model simulation in the DISPRIN25-DE model and the DISPRIN23-DE model is shown in Figure 2. The sequence of such analyses can be systematically explained as follows:

1 Input data training set: evapotranspiration $[E p(t)]$, rainfall $[P(t)]$, discharge observation $\left[Q_{\text {training }}(t)\right]$ and area of up-land watershed zone $[\mathrm{Au}]$, hill-slope $[\mathrm{Ah}]$, bottom-slope $[A b]$.

2 Setting DE parameters: dimension (D), number of individual (N), upper limit ( $\left.u b_{j}\right)$ and lower limit (lbj) parameter $\mathrm{s}$ value, and maximum generation number (maximum iteration). The value of $D$ is corresponding to the number of optimised DISPRIN model parameters. $D=25$ for the original DISPRIN model, and $D=23$ for the modified DISPRIN23 model.

3 Initialisation: the generation of the initial value of the $0^{\text {th }}$ generation vector, the $j^{\text {th }}$ variables, and $i^{\text {th }}$ vector can be represented by the following notation.

$$
x_{j, i, 0}=l b_{j}+\operatorname{rand}_{j}(, 1)\left(u b_{j}-l b_{j}\right)
$$

The random number is generated by the rand function, where the resulting number lies between $(0,1)$. Index j denotes the variable to $\mathrm{j}$. In the case of the original DISPRIN model, then $j$ will be worth $1,2,3, \ldots .25$, and in the case of the modified DISPRIN model, then $j$ will be worth $1,2,3, \ldots .23$. 
Fig. 2. Algorithm of the DISPRIN25-DE model and the DISPRIN23-DE model

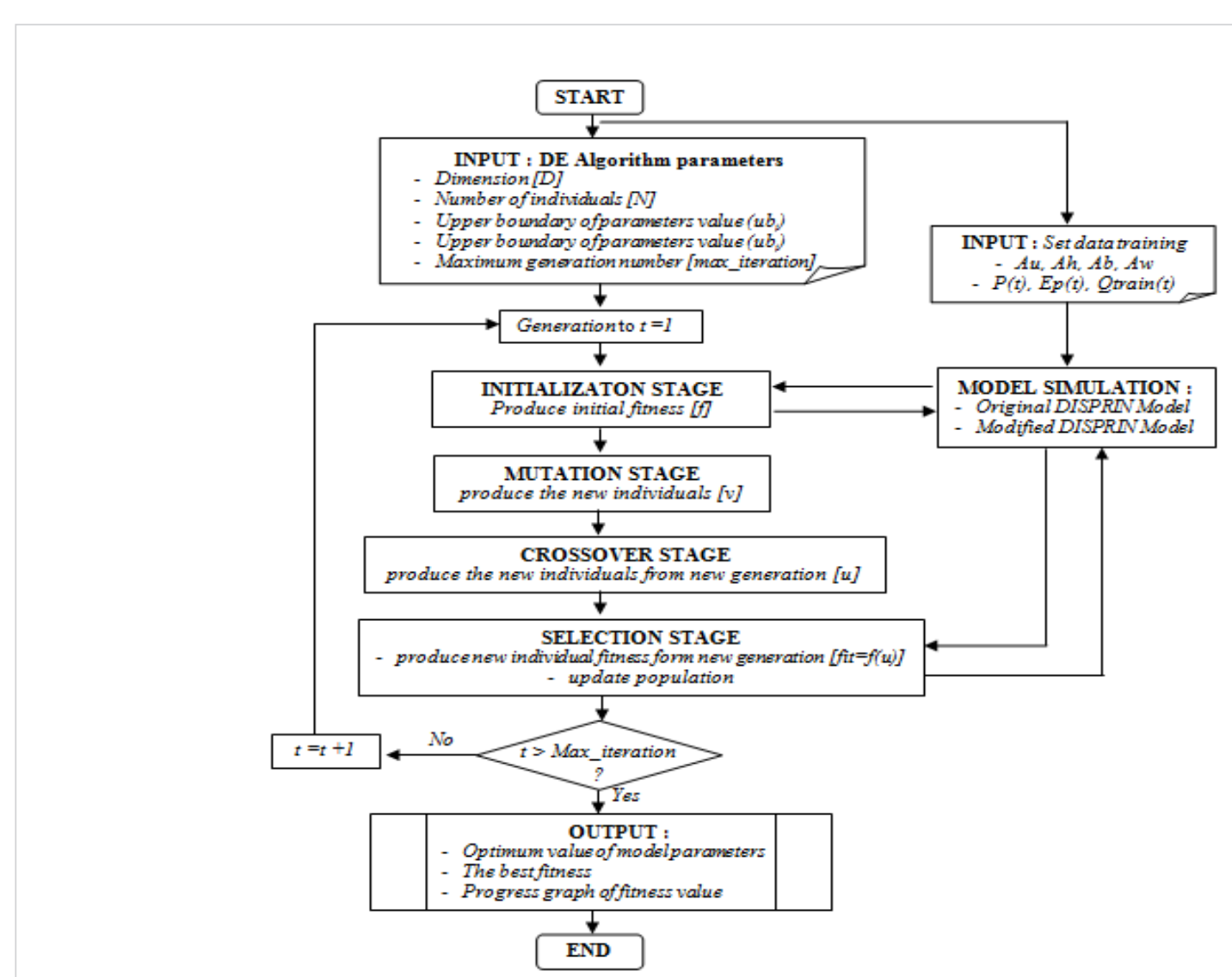

4 Mutation: this process will produce a population with a size of $N$ vector experiment. Mutation is done by adding two vector differences to the third vector by the following notation:

$$
v_{i, g}=x_{r 0, g}+F\left(x_{r 1, g}-x_{r 2, g}\right)
$$

It appears that two randomly selected vector differences need to be scaled before being added to the third vector, $\mathrm{x}_{\mathrm{r} 0, \mathrm{~g}}$. Factor scale $\mathrm{FE}(0,1)$ has positive real values that are useful for controlling population growth rates. The base vector index $\left(r_{0}\right)$ is determined by random means, the value of which is different from the index for the target vector i. Besides being different from each other and different from the index for the base vector and the target vector, the vector index of the difference between $r_{1}$ and $r_{2}$ is also chosen for once per mutant.
5 Crossover: at this stage, DE crosses every vector $\left(x_{i, g}\right)$ with a mutant vector $\left(v_{i, g}\right)$, to form the vector of $u_{i, g}$ with the formula:

$u_{i, g}=u_{j, i, g}=\left\{\begin{array}{l}v_{j, i, g} \rightarrow \text { if }\left(\operatorname{rand}(0,1) \leq \operatorname{Cror} j=j_{\text {rand }}\right. \\ x_{j, i, g} \rightarrow \text { if }\left(\operatorname{rand}(0,1)>\operatorname{Cr} \text { or } j \neq j_{\text {rand }}\right.\end{array}\right.$

6 Selection: if trial vector $\mathrm{u}_{\mathrm{i}, \mathrm{g}}$ has a goal function value smaller than the target destination function $\mathrm{x}_{\mathrm{i}, \mathrm{g}}$, then $\mathrm{u}_{\mathrm{i}, \mathrm{g}}$ will replace the position $\mathrm{x}_{\mathrm{i}, \mathrm{g}}$ in the population in the next generation. If the opposite happens, then the target vector will remain in its position in the population.

7 The process of analysis of items 4), 5), and 6) is repeated from the 0th generation to the defined maximum generation (max_iteration). Once the maximum generation is achieved, it will generate the best fitness value and the optimum parameter value. 


\section{Validation and verification the model}

Validation of the model is done by reapplying the original DISPRIN model and the modified DISPRIN model with an input set of data training and the optimum value of the model parameters which are generated from the calibration process using the DISPRIN25-DE model and the DISPRIN23-DE model.

Verification of the model is done in the same way, but using the data testing set as the input data. The discharge simulate from the output model will be compared with the discharge from data training, and deviation test using 3 indicators, namely; RMSE, Nash-Sutcliffe efficiency (NSE) and persistence model efficiency indicators (PME). NSE and PME are calculated by the formula:

$$
N S E=1-\frac{\sum_{t=1}^{N}\left(Q_{t}^{\text {sim }}-Q_{t}^{\text {obs }}\right)^{2}}{\sum_{t=1}^{N}\left(Q_{t}^{\text {obs }}-Q_{\text {mean }}^{\text {obs }}\right)^{2}}
$$

$$
P M E=1-\frac{\sum_{t=1}^{N}\left(Q_{t}^{\text {sim }}-Q_{t}^{o b s}\right)^{2}}{\sum_{t=1}^{N}\left(Q_{t}^{o b s}-Q_{t-1}^{o b s}\right)^{2}}
$$

Where: NSE - Nash-Sutcliffe efficiency;

PME - Persistency model efficiency;

$Q_{t}^{\text {obs }}$ - Discharge observation period $\mathrm{t},\left(\mathrm{m}^{3} / \mathrm{sec}\right)$;

$Q_{t-1}^{o b s}$ - Discharge observation period t- $1,\left(\mathrm{~m}^{3} / \mathrm{sec}\right)$;

$Q_{t}^{s i m}$ - Discharge simulation period $t,\left(\mathrm{~m}^{3} / \mathrm{sec}\right)$;

$Q_{\text {mean }}^{\text {obs }}$ - Average discharge observation, $\left(\mathrm{m}^{3} / \mathrm{sec}\right)$.

NSE provides normal model performance indicators in relation to the benchmark. NSE (dimensionless) measures the magnitude of the relative residual variant of the observation discharge variant. The optimal value is " 1 " and the value must be more than " 0 " to indicate the minimum acceptable. PME measures the magnitude of the relative residual variance (noise) for the variant of the model error obtained by using simple persistence. A simple persistence model is a minimal information situation in which we assume that the best estimate of the river flow in the next time step is given by the observational flow at the present time (Gupta et al., 1999).

\section{Case study}

Lesti watershed lies in the position $8^{\circ} 02^{\prime} 50^{\prime \prime}$ to $8^{\circ}$ $12^{\prime} 10^{\prime \prime}$ southern latitude and $112^{\circ} 42^{\prime} 58^{\prime \prime}$ to $112^{\circ} 56^{\prime}$ $21^{\prime \prime}$ east longitude. The position of Lesti watershed in the Brantas river system is shown in Figure 3. Lesti watershed has an area of $319.14 \mathrm{~km}^{2}$, divided into the up-land zone, the hill-slope zone and the bottom slope zone of $\mathrm{Au}=87.02 \mathrm{~km}^{2}, \mathrm{Ah}=104.89 \mathrm{~km}^{2}$ and $\mathrm{Ab}=127.23 \mathrm{~km}^{2}$, respectively.

Fig. 3. Location of the case study, Lesti watershed

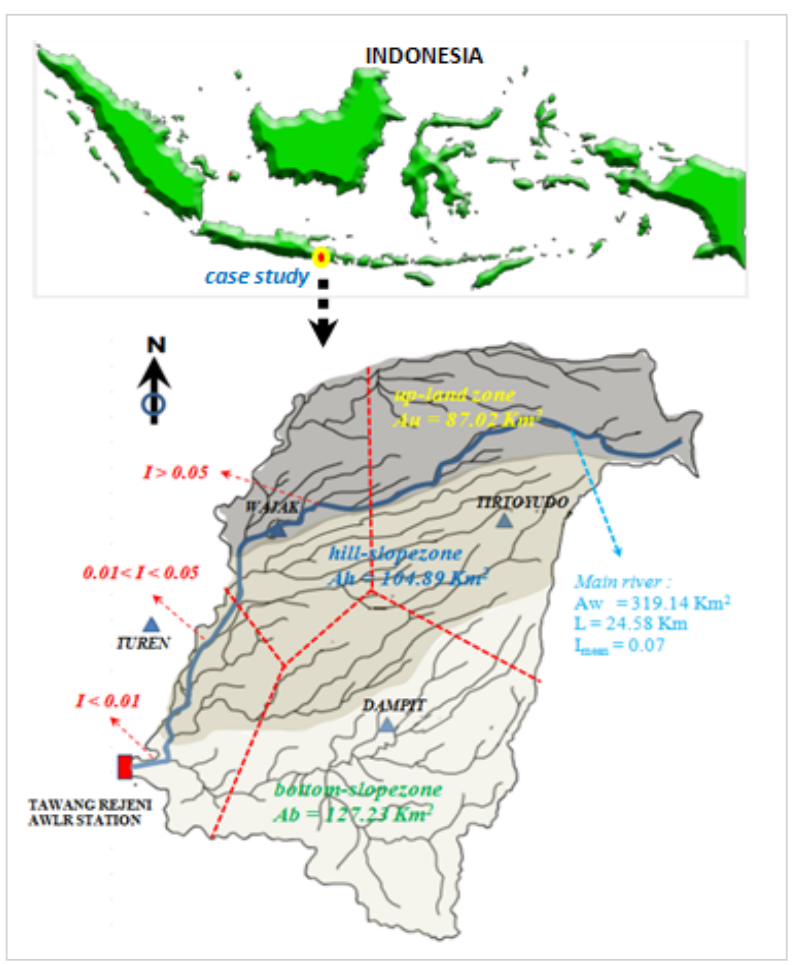

The data series of hydroclimatology in this study is the data recorded from January 1, 2011, to December 31, 2016. Evapotranspiration data were obtained from the analysis using the Penmann method with the data input in the form of wind velocity, temperature, humidity, and solar radiation. The climatic parameters data were obtained from the recording process in Karangkates climatology station.

There are 4 rain gauge stations covered in Lesti watershed, namely Dampit, Turen, Wajak and Tirtoyudo. The rainfall data were recorded in a daily period. The average regional rainfall was calculated by the polygon Thiessen method. The weighting factor of the polygon Thiessen of the four rainfall stations was 38\%, $9 \%, 19 \%$ and $34 \%$, respectively. The stream flow data from the recorded process in Tawangrejeni automatic 
water level record (AWLR) station is available in the hourly period. The transformation of the hourly discharge data into daily discharge is calculated by an algebraic average. Furthermore, the data series is divided into two groups. The first group is used as a training data set for parameter calibration and model validation process, abd the second group is used as a testing data set for the model verification process.

As a training data set is data recorded from 1 January 2007 to 31 December 2013, and as a testing data set is data recorded from 1 January 2014, to 31 December
2016. Daily period hydroclimatological data in the graphic form are shown in Figure 4. The rainfall training data has the mean, the minimum, the maximum, and the standard deviation of $6.17,0.00,77.76$, and $9.62 \mathrm{~mm} /$ day, and the rainfall testing data demonstrated $6.76,0.00,83.87,10.82 \mathrm{~mm} /$ day, respectively. The discharge training data have the mean, the minimum, the maximum, and the standard deviation of $17.44,5.91,35.03$, and $6.02 \mathrm{~m}^{3} / \mathrm{s}$, and the discharge testing data demonstrated 18.59, 5.99, 37.58, and $6.87 \mathrm{~m}^{3} / \mathrm{s}$, respectively.

Fig. 4. Daily training and testing data sets

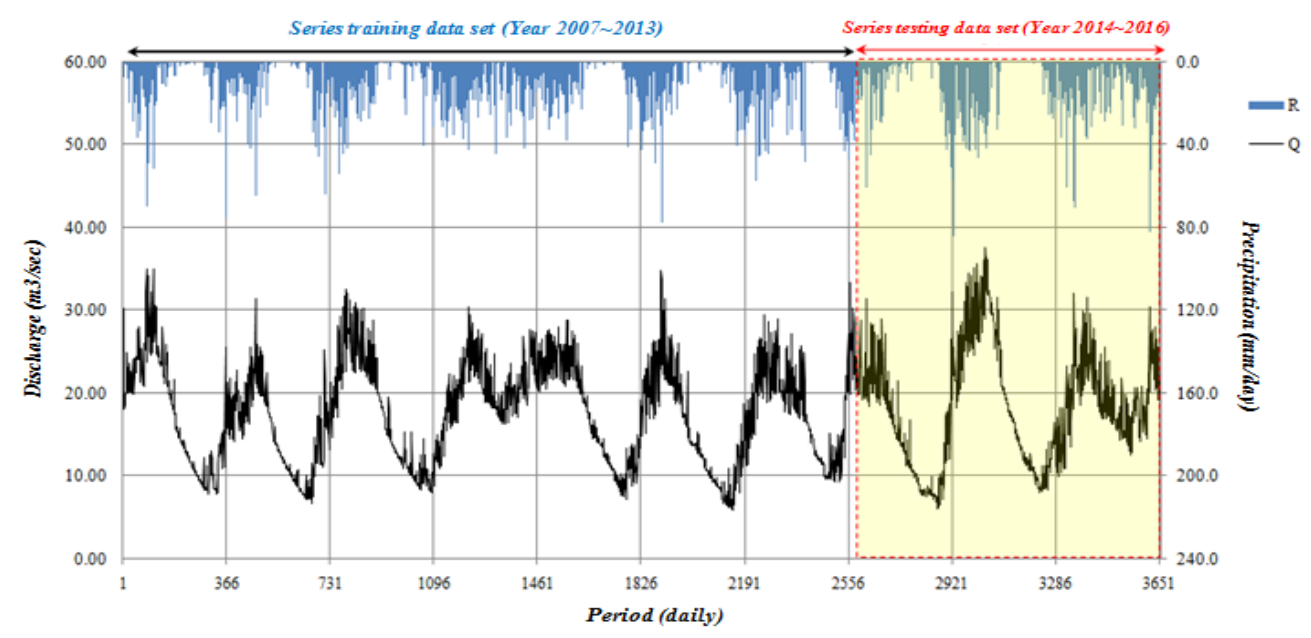

\section{Results and discussion}

The DISPRIN model implementation reference is still very limited; thus, the feasibility limit of the parameters value becomes difficult to define. Referring to the implementation of Sugawara's Tank model from various references, the lower boundary $\left(l b_{j}\right)$ and the upper boundary ( $u b_{j}$ ) outlet coefficient are $l b_{j-} \mathrm{C}=0$ and $u b j \_C=1$, respectively. The value of the initial water level and the height of the outlet is a positive number, and varies depending on the watershed hydrological characteristics being analysed. In this article, the lower boundary initial parameter of the storage and the position of the minimum tank outlet $\left(l b_{j} H\right)$ is set to " 0 " and the maximum value $\left(u b_{j} H\right)$ is approached by trial and error. The results of the analysis using the application of the DISPRIN25-DE model and the DISPRIN23-DE model generated the relevant $u b_{\llcorner} H$ value of $800 \mathrm{~mm}$. Furthermore, the analysis, using the input value $l b_{j} C=0, u b_{j} C=1, l b_{j} H=0, u b_{j} H=800 \mathrm{~mm}$, parameters of individual $(\mathrm{N})=350$, and maximum generation (Iter_max $)=250$, gives the result as shown in Table 2, Table 3 and Figure 5 to Figure 10.

In the calibration stage of the original DISPRIN model parameter performed by applying the DISPRIN25-DE model, it produces the best fitness value $0.045 \mathrm{~m}^{3} / \mathrm{s}$ achieved in 147.45 minutes. The calibration of the modified DISPRIN model parameters by applying the DISPRIN23-DE model generates the best fitness value $0.036 \mathrm{~m}^{3} / \mathrm{s}$ and is achieved within 139.60 minutes. 
Table 2. Comparison of performance model indicators

\begin{tabular}{|c|c|c|c|c|c|}
\hline \multirow{2}{*}{ Performance of the indicator model } & \multirow{2}{*}{ Unit } & \multicolumn{2}{|c|}{ Original DISPRIN model } & \multicolumn{2}{|c|}{ Modified DISPRIN model } \\
\hline & & Validation stage & Verification stage & Validation stage & Verification stage \\
\hline [1] & {$[2]$} & {$[3]$} & {$[4]$} & {$[5]$} & {$[6]$} \\
\hline Root Mean Square Error, RMSE & {$[\mathrm{m} 3 / \mathrm{s}]$} & 0.045 & 0.091 & 0.036 & 0.069 \\
\hline Nash-Sutcliffe Efficiency, NSE & {$[-]$} & 0.784 & 0.713 & 0.861 & 0.828 \\
\hline Persistence Model Efficiency, PME & {$[-]$} & -0.024 & -0.264 & 0.307 & 0.0269 \\
\hline Time of iteration & [minute] & 147.45 & - & 139.60 & - \\
\hline
\end{tabular}

Table 3. Optimum value of DISPRIN model parameters

\begin{tabular}{|c|c|c|c|c|c|}
\hline \multirow{2}{*}{ Parameters } & \multirow{2}{*}{ Description } & \multicolumn{2}{|c|}{ Constraint } & \multicolumn{2}{|c|}{ Optimum Value } \\
\hline & & LB & $\mathrm{UB}$ & DISPRIN25-DE & DISPRIN23-DE \\
\hline$D A 1$ & height of surface outlet up-land zone & 0.00 & 800.00 & 800.00 & 0.00 \\
\hline$D B 1$ & height of sub surface outlet up-land zone & 0.00 & 800.00 & 212.69 & 783.34 \\
\hline$C A O$ & infiltration coefficient up-land zone & 0.00 & 1.00 & 0.000 & 0.097 \\
\hline$C B O$ & sub surface coefficient up-land zone & 0.00 & 1.00 & 0.360 & 0.215 \\
\hline$C B 1$ & percolation coefficient up-land zone & 0.00 & 1.00 & 0.724 & 0.090 \\
\hline$S A=0$ & initial storage of Tank $A$ & 0.00 & 800.00 & 215.15 & 800.00 \\
\hline$S B \_0$ & initial storage of Tank $B$ & 0.00 & 800.00 & 165.17 & 139.82 \\
\hline$D C l$ & height of surface outlet hill-slope zone & 0.00 & 800.00 & 0.02 & 529.86 \\
\hline$D D 1$ & height of sub surface outlet hill-slope zone & 0.00 & 800.00 & 800.00 & 0.12 \\
\hline $\mathrm{CCO}$ & infiltration coefficient hill-slope zone & 0.00 & 1.00 & 0.729 & 0.924 \\
\hline$C D O$ & sub surface coefficient hill-slope zone & 0.00 & 1.00 & 0.480 & 0.221 \\
\hline$C D 1$ & percolation coefficient hill-slope zone & 0.00 & 1.00 & 1.000 & 0.054 \\
\hline$S C$ & initial storage of Tank $C$ & 0.00 & 800.00 & 800.00 & 196.95 \\
\hline$S D \_0$ & initial storage of Tank D & 0.00 & 800.00 & 706.11 & 227.50 \\
\hline$D E 1$ & height of surface outlet bottom-slope zone & 0.00 & 800.00 & 0.00 & 623.01 \\
\hline$D F 1$ & height of sub surface outlet bottom-slope zone & 0.00 & 800.00 & 800.00 & 154.56 \\
\hline$C E O$ & infiltration coefficient bottom-slope zone & 0.00 & 1.00 & 0.000 & 0.006 \\
\hline CFO & sub surface coefficient bottom-slope zone & 0.00 & 1.00 & 0.132 & 0.005 \\
\hline$C F 1$ & percolation coefficient bottom-slope zone & 0.00 & 1.00 & 0.269 & 0.000 \\
\hline$S E \_0$ & initial storage of Tank $E$ & 0.00 & 800.00 & 419.85 & 320.50 \\
\hline$S F O$ & initial storage of Tank $F$ & 0.00 & 800.00 & 659.21 & 800.00 \\
\hline$C G$ & channel flow coefficient & 0.00 & 1.00 & 0.165 & 0.010 \\
\hline$S G O$ & initial storage of Tank $G$ & 0.00 & 800.00 & 0.00 & 457.89 \\
\hline $\mathrm{CH}$ & channel flow coefficient & 0.00 & 1.00 & 0.006 & \\
\hline SH_O & initial storage of Tank $H$ & 0.00 & 800.00 & 376.37 & \\
\hline
\end{tabular}


The progress of achieving the best fitness values from the analysis of both models is shown in Figure 5 and Figure 6. This phenomenon indicates that the parameter calibration process in the DISPRIN23-DE model is more effective than the DISPRIN25-DE model in terms of accuracy and speed in achieving convergent conditions. The optimum values of the original DISPRIN model parameters and the modified DISPRIN model parameters generated from the optimisation process using the DE algorithm are shown in Table 3. Although using the lower boundary input (LB) and the upper boundary (UB) are the same values for all

Fig. 5. Progress of the best fitness value from the DISPRIN25-DE model in the calibration stage

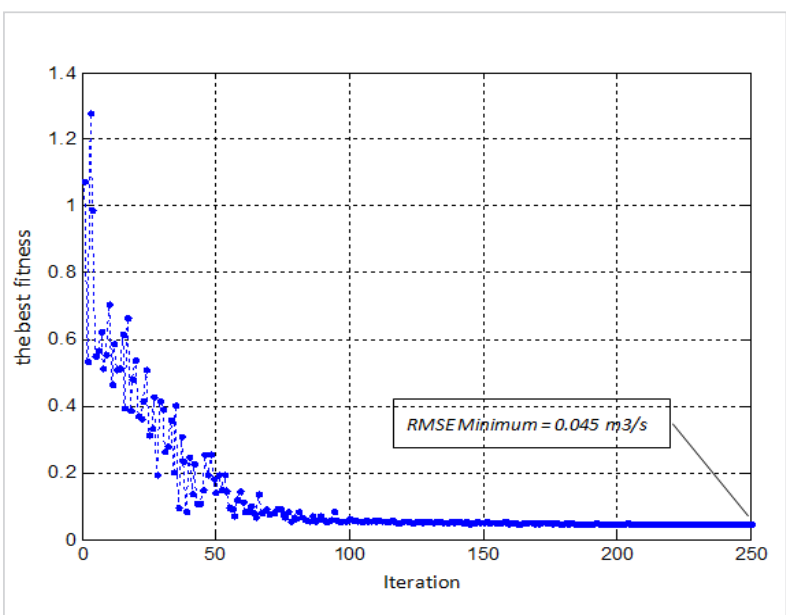

Fig. 6. Progress of the best fitness value from the DISPRIN23-DE model in the calibration stage

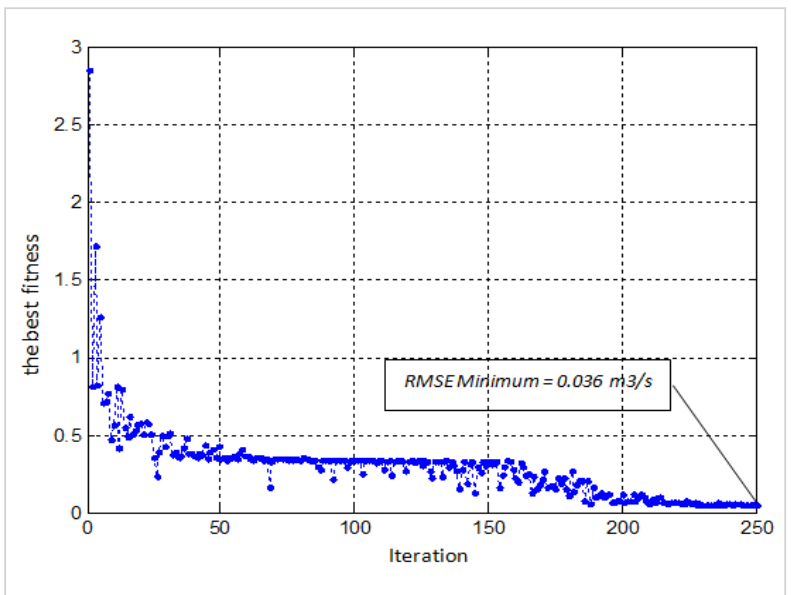

parameters, the optimal value of all parameters in the two models shows different results because both models have different simulation schemes.

Model validation is done by applying the simulation of the original DISPRIN model and the modified DISPRIN model. The model validation process involves the training data set and the optimum value of the parameters of the two models resulting from the calibration process as the input data. Model verification is done in the same way, but uses a testing data set as input data. The comparison of the model performance indicator values in the model validation and model verification is shown in Table 2.

In the validation stage, both models produce RMSE and NSE values of equal magnitude, which means that both models have the same level of performance as good, but the PME indicator shows significant differences in the value. The application of the modified DISPRIN model results in a larger PME value than the original DISPRIN Model. The NSE value $>0.8$ indicates that both models are relevant to be applied in solving this problem.

Comparison of the discharge training curve and the discharge model curve is shown in Figure 7. The discharge curve from the outputs of the two models at the validation stage can follow the seasonal trend discharge training curve. The output discharge curve from original DISPRIN models (green line) at low flow conditions, normal flow and high flow tend to place themselves in a moderate position. The sharp fluctuation of flows that occurs due to the high rainfall intensity in the daily period cannot be responded well. This condition is the cause of the low value of the resulting PME indicator. The discharge curve from the output modified DISPRIN models (red line) can show better results. The presence of sharp fluctuations that occur due to high rainfall intensity can be responded well. At low flow and normal flow conditions, the three curves appear to coincide, but at high flow conditions, only the discharge curve from the modified DISPRIN model approaches the observation discharge curve.

The plotting of discharge training and the discharge model as shown in Figure 8 shows that the performance of the modified DISPRIN model is better. Data distribution tends to approach the line of equation with $r^{2}=0.91$, and in the original DISPRIN model with $r^{2}=$ 
Fig. 7. Comparison of curve $Q_{-}$training and $Q_{-}$model in the validation stage

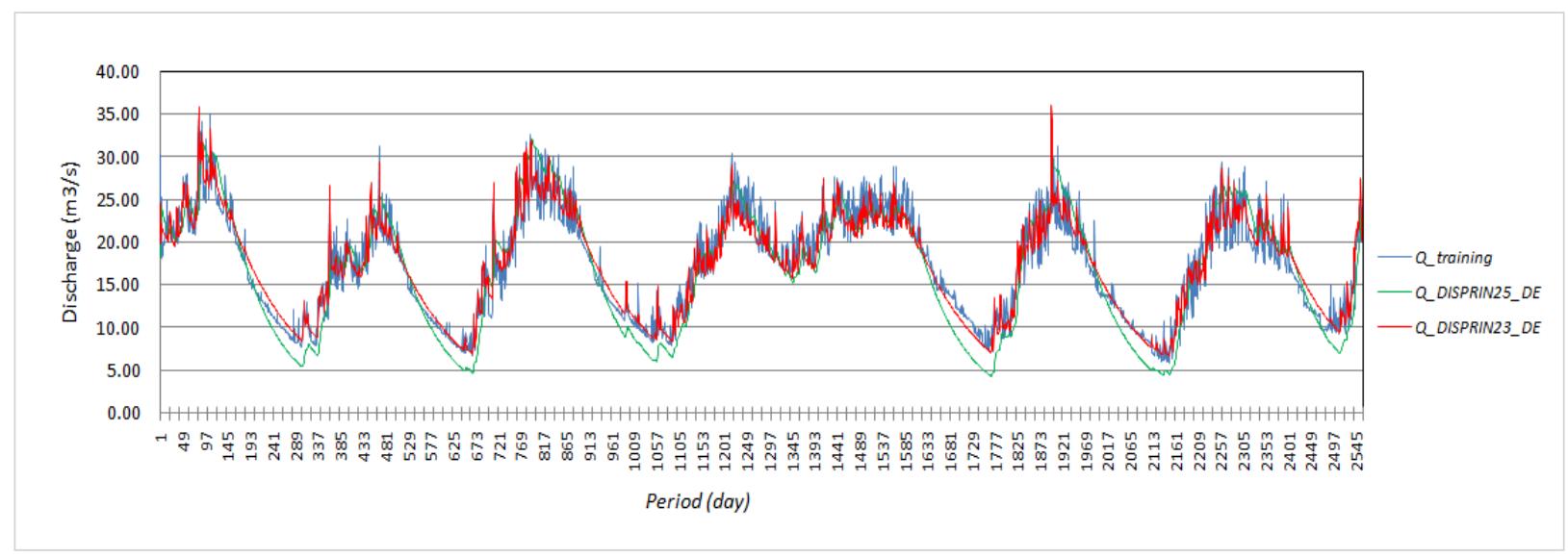

Fig. 8. Plotting of distribution $Q_{-}$training and $Q_{-}$model in the validation stage
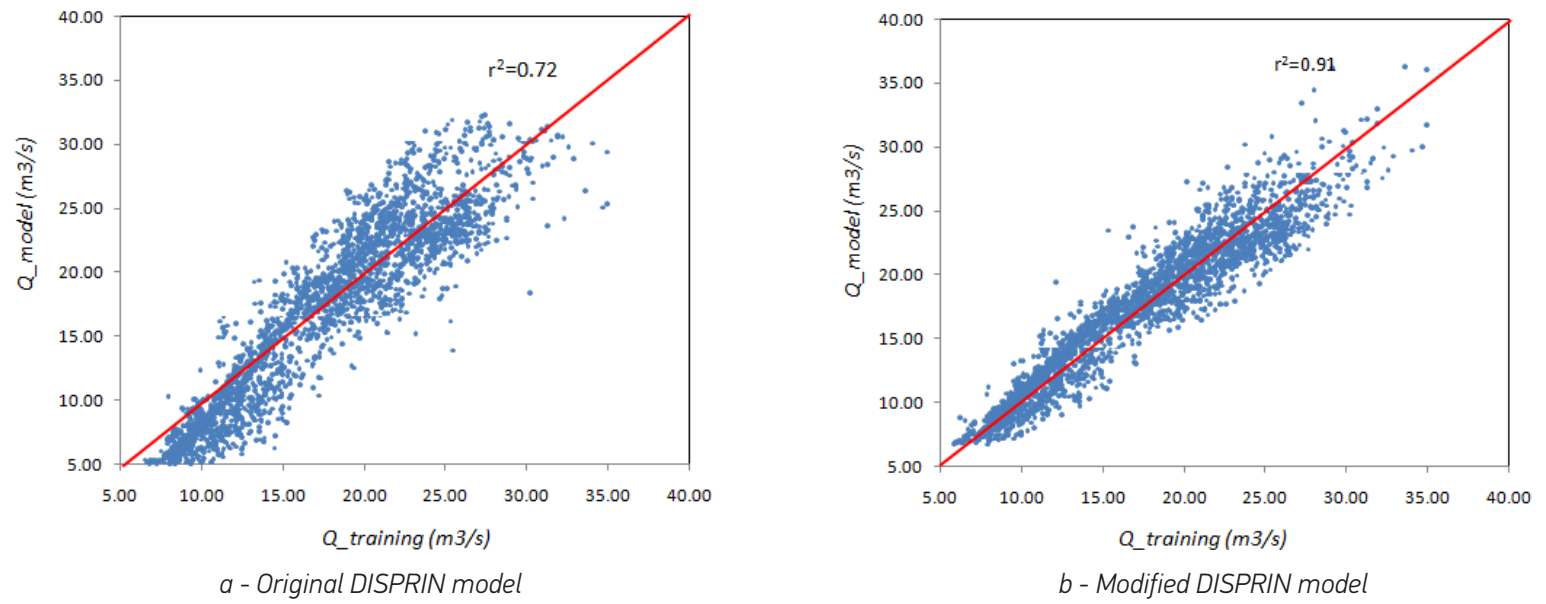

0.72. This result further reinforces the conclusion that the modified DISPRIN model can show more effective performance applied to watersheds with sharp fluctuations than the original DISPRIN model. Based on the simulation scheme as shown in Figure 1, the factor of the translation effect (channel flow) in the original DISPRIN model is a distinguishing factor on the performance of both models. The existence of the factor of the translation effect presented by a tank with a bottom outlet actually becomes an obstacle to model efforts in anticipating the occurrence of sharp fluctuations of the flow. Rapid flow changes due to the high rainfall intensity occurring in the accumulation of up-land zone tanks, hill-slope and bottom-slope are muted in the translation effect tanks and are streamed slowly. This suggests that attempts to modify the original DISPRIN model (DISPRIN25 model) into the modified DISPRIN model (DISPRIN23 model) have shown better performance when applied to small watersheds that have a rather sharp fluctuation rate as in Lesti watershed.

The analysis results of the model verification stage are shown in column [4] and column [6] of Table 2, the comparison of discharge testing and the discharge model is graphically shown in Figure 9 and Figure 10. The NSE and PME values resulting from model verification tend to be smaller compared with 
the model validation analysis results, which means that both models show a decrease in performance. This is understandable because the statistical characteristics of set data training differ from data testing. The NSE value $>0.7$ indicates that the results of the analysis of both models are still acceptable. The original DISPRIN model analysis at the verification stage resulted in a worse performance. The distribution of discharge testing and the discharge model as shown in Figure 10 is further away from the equation line, and yields the determination coefficient $\left(r^{2}\right)=0.59$. Figure 9 shows that the flow curve from the model output is also unable to respond to the sharp fluctuations in flow. This condition makes the PME value smaller, even negative. This indicates that the original DISPRIN model is incorrect when applied to a responsive watershed that has a sharp fluctuation flow rate. Analysis of the modified DISPRIN model can result in better performance. The verification stage yields a coefficient of determination $\left(r^{2}\right)=0.71$. This further reinforces that the modified DISPRIN model is relevant enough when applied to responsive watersheds that have sharp fluctuation rates as well as daily period flow characteristics in Lesti watershed.

Fig. 9. Comparison of $Q_{-}$testing and $Q_{-}$model curves in the verification stage

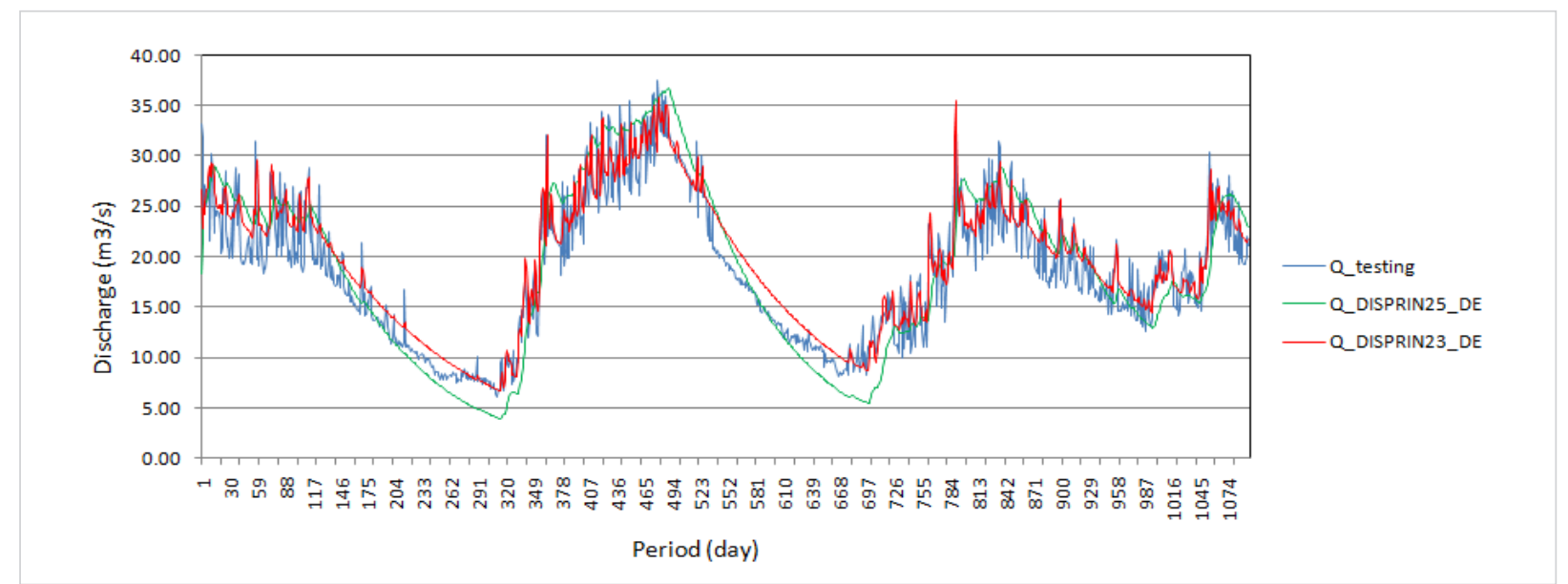

Fig. 10. Plotting of distribution $Q_{-}$testing and $Q_{-}$model in the verification stage
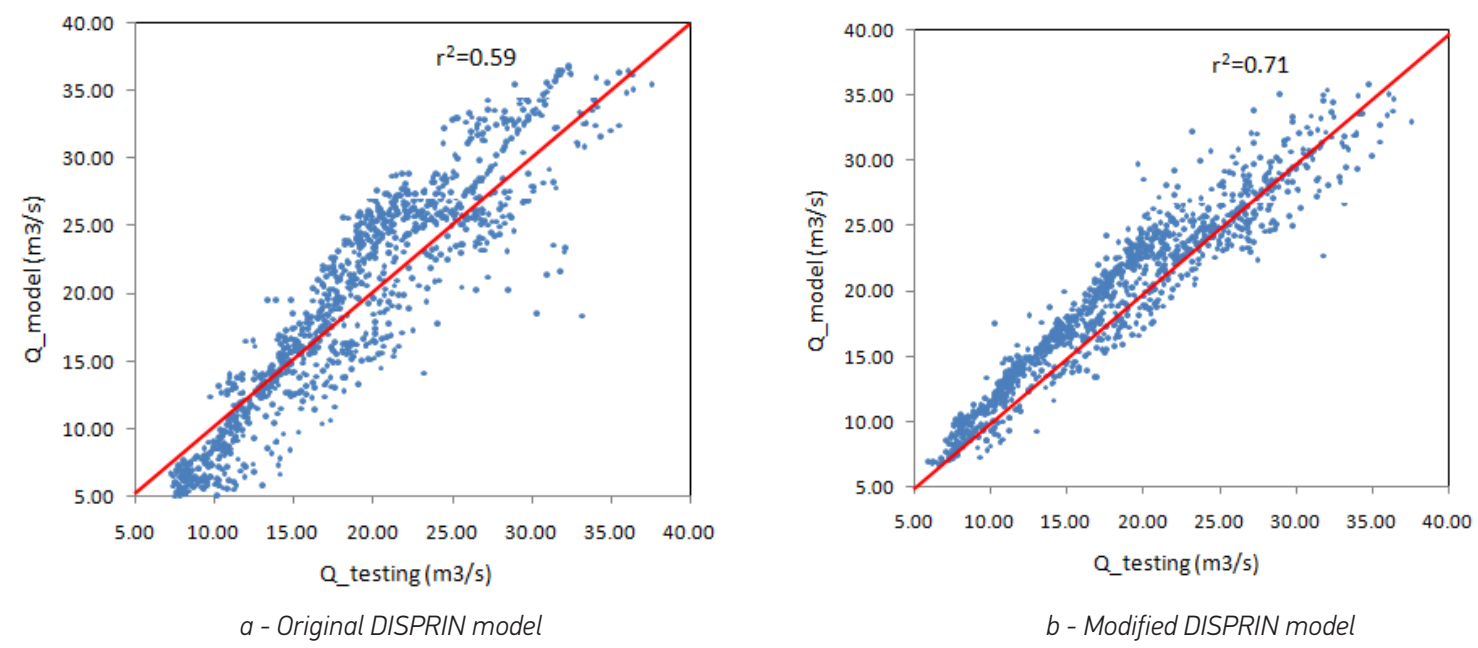


\section{Conclusion}

Modifying the original DISPRIN model (DISPRIN25 model) to a modified DISPRIN model (DISPRIN23 model) by ignoring the translation effect factor can be a solution to extend the daily period debit data series on small watersheds that have sharp flow fluctuations. Based on the indicators RMSE, NSE, and PME, the modified DISPRIN model combined with the DE algorithm is proven to work more effectively. Testing the model on Lesti watershed $\left(319.14 \mathrm{~km}^{2}\right)$ using database input daily periods can show very good performance, both at the calibration stage and the validation stage. In the application of the original DISPRIN model, the resulting flow curve can follow the seasonal trend of the observation flow curve. Low flow conditions, normal flow and high flow curves resulting from the original DISPRIN model tend to put themselves in a moderate position. Sharp flow fluctuations that occur due to high rainfall intensity in the daily period cannot be responded properly. This condition is the cause of the low value of PME produced. The modified DISPRIN model can correct the weaknesses of the original DISPRIN model. Application of this model can provide a better PME value. Sharp flow fluctuations due to short periods of high intensity rain can respond better. This proves that the modified DISPRIN model is more relevant when applied to a small watershed with fast flow responses as occurs in tropical rivers in the archipelago.

\section{Acknowledgment}

Researchers would like to thank the DPPM University of Muhammadiyah Malang for providing facilities for the implementation of this research. Hopefully, the results of this research can contribute positively to the development of science and technology.

\section{References}

Bao H. J., Wang L., Li Z. J., Zao L. N and Guo-ping Zhang (2008) Hydrological daily rainfall-runoff simulation with BTOPMC model and comparison with Xin'anjiang model, Water Science and Engineering, 2010, 3(2): 121-131, doi:10.3882/j.issn.1674-2370.2010.02.001, http://www.waterjournal.cn, e-mail: wse2008@vip.163.com

Chen C., Shrestha D. L., Perez G. C., Solomatine D. (2006) Comparison of methods for uncertainty analysis of hidrologic models, 7th International Conference on Hydroinformatics HIC 2006, Nice, FRANCE.

Darikandeh D., Akbarpour A., Bilondi M. P. and Hashemi S. R. (2014) Automatic calibration for Estimation of The Parameters of Rainfall - Runoff Model, SCIJOUR, Journal of River Engineering, Volume 2, Issue 8 2014, http://www.scijour.com/jre.

Gupta H. V., Sorooshian S. and Yapo P. O. (1999) Status of automatic calibration for hydrologic Models : Comparation With Multi Level Expert Calibration, Journal of Hydrologic Engineering, Vol. 4, No. 2, April, 1999. ASCE, ISSN:1084-0699/99/0002-0135-0143. https://doi.org/10.1061/(ASCE)1084-0699(1999)4:2(135)
Huang X. L. and Xiong J. (2010) Parameter Optimization of Multi-tank Model with Modified Dynamically Dimensioned Search Algorithm, Proceedings of the Third International Symposium on Computer Science and Computational Technology (ISCSCT '10), Jiaozuo, P. R. China, 14-15,August 2010, pp. 283-288, ISBN 978-952-5726-10-7, (c) 2010 ACADEMY PUBLISHER, APPROC-CS-10CN007.

Hsu P. Y. and Yeh Y. L. (2015) Study on Flood Para-Tank Model Parameters with Particle Swarm Optimization, Journal of Information Hiding and Multimedia Signal Processing, Ubiquitous International Volume 6, Number 5, September 2015, @ 2015 ISSN 2073-4212.

Jonsdottir H., Madsen H. and Palsson O. P (2005) Parameter estimation in stochastic rainfall-runoff models, ELSEVIER, Journal of Hydrology 326 (2006) pp. 379-393. https://doi.org/10.1016/j.jhydrol.2005.11.004

Kenji T., Yuzo O., Xiong J. and Koyama T. (2008) Tank Model and its Application to Predicting Groundwater Table in Slope, Chine- 
se Journal of Rock Mechanics and Engineering, Vol.27 No.12 Dec, 2008, CLC number : pp. 642.22 Document code : A Article ID : 1000-6915(2008)12-2501-08.

Kim Oong H., Paik Kyung R., Kim Hung S. and Lee D. R. (2005) A Conceptual Rainfall - runoff Model Considering Seasonal Variation, HYDROLOGICAL PROCESSES, DECEMBER 2005 Impact Factor: 2.68 · DOI: 10.1002/hyp.5984ADVANCES IN HYDRO-SCIENCE AND -ENGINEERING, VOLUME VI, http://www.researchgate.net/publication/ 227599393.

Kuok K. K., Harun S. and Chiu P. Ch. (2011) Comparison of Particle Swarm Optimization and Shuffle Complex Evolution for Auto-Calibration of Hourly Tank Model's Parameters, Int. J. Advance. Soft Comput. Appl., Vol. 3, No. 3, November 2011, ISSN 2074-8523; Copyright (C) ICSRS Publication, 2011, www.i-csrs.org.

Ngoc T. A., Hiramatsu K. and Haramada M. (2012) Optimizing Parameters for Two Conceptual Hydrological Models Using a Genetic Algorithm: A Case Study in the Dau Tieng River Watershed, Vietnam, JARQ 47 (1), pp. 85-96 (2013) http://www. jircas.affrc.go.jp. https://doi.org/10.6090/jarq.47.85

Piotrowski A., Napiorkowski M., Napiorkowski J., Osuch M. and Kundzewicz Z. (2016) Are modern metaheuristics successful in calibrating simple conceptual rainfall-runoff models?", Hydrological Siences Journal, Volume 62, 2017 Issue 4, IAHS, Taylor \& Francis online. ttps://doi.org/10.1080/02626667.20 16.1234712

Ramires J. D., Camacho R., McAnally W. and Martin J. (2012) Parameter uncertainty methods in evaluating a lumped hydrological model, Obrasy Proyectos 12, pp. 42-56. https://doi. org/10.4067/S0718-28132012000200004

Saibert J. (2000) Multi-criteria Calibration of Conseptual Runoff Model Using a Genetic Algorithm, Hydrology and Earth System Sciences, 4(2), pp. 215-224 (2000) EGS. https://doi. org/10.5194/hess-4-215-2000

Santos C. A. G. (2011) Application of a particle swarm optimization to the Tank Model, Risk in Water Resources Management (Proceedings of Symposium H03 held during IUGG2011 in Melbourne, Australia, July 2011) (IAHS Publ. 347, 2011).
Setiawan B., Fukuda T. and Nakano Y. (2003) Developing Procedures for Optimization of Tank Model's Parameters, Agricultural Engineering International : the CIGR Journal of Scientific Research and Development.

Shaw E. M. (1985) Hydrology in Practice, Van Nostrand Reinhold (UK) Co. Ltd.

Sulianto (2018) Automatic calibration and sensitivity analysis of DISPRIN model parameters: A case study on Lesti watershed in East Java, Indonesia, Journal of Water and Land Development, No. 37 (IV-VI) pp. 141-252, Polish Academy of Science (PAN) Comitte on Agronomic Sciences, Section of Land Reclamation and Environmental Engineering in Agriculture, Institutof Technology and Life Sciences (ITP). https://doi.org/10.2478/jwld-2018-0033 Tolson B. A. and Shoemaker C. A. (2007) Dynamically dimensioned search (DDS) algorithm for computationally efficient watershed model calibration, ATER RESOURCES RESEARCH, VOL. 43, W01413, doi:10.1029/2005WR004723, 2007, Copyright 2007 by the American Geophysical Union. 00431397/07/2005WR004723\$09.00

Uhlenbrook S., Seibert J., Leibundgut C., Rodhe A. (1999) Prediction uncertainty of conceptual rainfallrunoff models caused by problems in identifying model parameters and structure, Hydrological Sciences-Journal-des Sciences Hydrologiques, 44(5) October. https://doi.org/10.1080/02626669909492273

Wang W. C., Cheng C. T., Chau K. W. and Xu D. M. (2012) Calibration of Xinanjiang model parameters using hybrid genetic algorithm based fuzzy optimal model, (c) IWA Publishing 2012, Journal of Hydroinformatic, 14.3 - 2012, 785 W-C. https://doi. org/10.2166/hydro.2011.027

Zhang X., Srinivasan R., Zhao K. and Liew M. V. (2008) Evaluation of global optimization algorithms for parameter calibration of a computationally intensive hydrologic model, HYDROLOGICAL PROCESSES, Published online in Wiley InterScience, www. interscience.wiley.com). https://doi.org/10.1002/hyp.7152

Zhang X., Hörmann G. , Fohrer N. and Gao J. (2012) Parameter calibration and uncertainty estimation of a simpie rainfail-runoff modei in two case studies, (C) IWA Publishing 2012, Journal of Hidroinformatics 14.4 2012. https://doi.org/10.2166/ hydro.2012.084 